\title{
A lógica social do voto correto no Brasil
}

André Bello

\section{Introdução}

A universalização democrática se confirmou (Huntington, 1994), de tal modo que os interesses dos estudiosos da área se voltam não mais às transições e consolidações do sistema político. O foco definitivamente é a qualidade das jovens democracias, em especial as dos países da América Latina. Uma forma de especificar a qualidade democrática é através do correct voting (voto correto) - o eleitor escolhe o candidato que melhor o representa e que fornecerá os maiores benefícios (Lau e Redlawsk, 2006).

$\mathrm{O}$ voto correto, por definição, exige que os eleitores estejam minimamente bem informados sobre as ações dos governantes e dos oponentes e também aptos para reconhecer e assimilar os próprios valores e interesses políticos. Assim, o voto correto liga-se intimamente com a informação, de maneira que o processo informativo se torna fundamental para a qualidade da escolha eleitoral.

Essa colocação exige uma análise acerca dos canais de informação e, mais especificamente, como esse processo informativo afeta as decisões de qualidade; nesse caso, o voto correto. A comunicação política é dominada por dois tipos de canais informativos: a mídia tradicional, incluindo a internet, e as redes interpessoais - amigos, familiares, vizinhos e até desconhecidos. Para a finalidade deste artigo, somente as redes interpessoais serão analisadas. A ideia por trás das redes interpessoais é que existe uma mediação entre os veículos de massa e os cidadãos, desempenhada por membros da comunidade que exercem o papel de líderes de opinião, cujo modelo é chamado de twostep-flow of communication (Katz, 1957; Katz e Lazarsfeld, 1995; Lazarsfeld, Berelson e Gaudet, 1948).

Os indivíduos, no entanto, estão inseridos em contextos sociais e políticos que determinam a probabilidade das interações sociais e, consequentemente, o fluxo informacional. O contexto compreende uma composição social que muitas vezes se refere a um espaço geográfico, como bairro, clube e igreja (Putnam, 1966; Huckfeldt e Sprague, 1995). O contexto pode se referir também à estrutura institucional ou organização política (Lupia e McCubbins, 1998). Este artigo aborda apenas o contexto social, sendo o bairro usado como a medida central.

Cabe aqui enfatizar que existem diferenças conceituais e operacionais entre a rede e o contexto social, embora a literatura, algumas vezes, coloque-as em sobreposição. O contexto social é exógeno ao indivíduo, isto é, está além do alcance do controle individual, restringindo ou ampliando as interações individuais. Já a rede social 
corresponde à relação entre os indivíduos e as suas próprias escolhas. Os cidadãos exercem um poder discricionário sobre a rede de contatos estabelecida pelas várias configurações sociais. Esse é o enfrentamento conceitual deste artigo, separando estrategicamente rede e contexto social (Huckfeldt e Sprague, 1995; Baker, Ames e Rennó, 2006).

Assim, coloca-se a questão: as interações individuais são instrumentos que facilitam o "voto correto" do eleitor ou, ao contrário, criam empecilhos e obstáculos para atingir esse fim? Já que informação é importante para o voto correto e redes sociais são mecanismos de disseminação de informações, mesmo que contaminadas pelas preferências daqueles que compõem as redes, cabe investigar como as interações individuais afetam as escolhas individuais.

A estratégia central deste artigo se dá em dois eixos: por um lado, investigar se os brasileiros votam corretamente, apesar do sistema partidário fragmentado e da representação proporcional de lista aberta, os quais incentivam a personalização do voto (Ames, 1995, 2003; Mainwaring, 1991); por outro lado, o interesse é conhecer o impacto da rede e do contexto social sobre o voto correto. O argumento que defendo aqui é que, no Brasil, em razão da baixa identidade partidária, do sistema multipartidário e das características culturais, o voto correto existe por meio das interações individuais. Existe uma lógica social para o voto correto, portanto.

Esses eixos centrais desdobram-se em objetivos específicos que consistem em testar os efeitos dos distintos atributos (conflito e diversidade) de rede e contexto social sobre o voto correto. Essa discussão será aprofundada na seção teórica, "Redes interpessoais". Com essa proposta teórica, cuja organização se dá entre as teorias de rede, contexto social e voto correto, pretende-se para o caso brasileiro, de um lado, introduzir a discussão do voto correto sob o prisma da qualidade democrática e, de outro lado, conciliar explicações para o comportamento eleitoral baseadas em fatores estruturais e individuais.

Os resultados sugerem uma lógica social para o voto correto na eleição presidencial de 2002, pelo menos para as cidades de Juiz de Fora e Caxias do Sul. Esses resultados não podem ser generalizados para todo o país por não se tratar de uma amostra nacional. Há uma limitação no que diz respeito à validade externa. Contudo, esse banco de dados dá a oportunidade de capturar os efeitos de rede e contexto social de forma mais direta, pois os respondentes foram agrupados por bairros.

\section{Voto correto - uma medida de qualidade da democracia}

A qualidade democrática exige um governo responsivo com as demandas dos cidadãos (Diamond e Morlino, 2005; Rennó, 2010; Rennó et al., 2011), e o voto correto tem potencial de gerar esse elo de responsabilização entre representantes e representados, um requisito mínimo para o funcionamento da democracia (Dahl, 1989; 
Dahl, 1997; Berelson, 1952). Isso porque se espera que os cidadãos que votam corretamente sejam mais atentos e controladores das ações políticas. No que tange ao outro lado do procedimento democrático, os governos possuem maior probabilidade de satisfazer as expectativas da população, isto é, de identificar o que a sociedade deseja e introduzir políticas públicas em consonância com esses interesses e preferências. Nesse sentido, o conceito do voto correto é alçado a um microfundamento da qualidade democrática. Mais precisamente, considera-se o voto correto como uma atitude racional que legitima o governo e produz efeitos inclusive para a responsividade. Em suma, o ato de votar corretamente é uma precondição para uma adequada representação política.

O significado do voto correto remete a valores, crenças e preferências dos eleitores em termos de políticas públicas e do candidato. Dito de outra forma, o voto correto ocorre quando o voto dado a certo candidato corresponde ao que seria esperado dadas as preferências políticas e valorativas desse eleitor (Lau e Redlawsk, 1997). Adicionalmente, os autores vinculam a atitude de votar corretamente aos atalhos informativos, quando definem o voto correto como uma escolha que teria sido feita por meio de condições de informações completas. É a probabilidade de o eleitor votar em um candidato caso estivesse totalmente informado sobre este (Lau, Andersen e Redlawsk, 2008). Trata-se de uma medida binária e como tal assume-se o seguinte axioma: se o eleitor escolhe o candidato baseado nos seus valores e interesses, ele votou corretamente. Do contrário, votou incorretamente.

Os primeiros estudos do voto correto foram realizados nos Estados Unidos, no final da década de 1990 (Lau e Redlawsk, 1997, 2006; Lau, Andersen e Redlawsk, 2008). Usando a combinação de um experimento e dados da American National Election Studies (Anes) entre os anos de 1972 e 2004, Lau e Redlawsk (1997, 2006) indicaram positivamente a existência do voto correto entre os eleitores norte-americanos. Para dados do survey, a média do voto correto foi da ordem de $75 \%$, enquanto no experimento esse índice atingiu 70\%. A fim de refinar esses resultados, Lau, Andersen e Redlawsk (2008) testaram quatro variáveis como pressupostos do voto correto: motivação política, conhecimento político, uso de heurísticas e volume da campanha política. Os resultados apontaram que todos esses pressupostos foram estatisticamente positivos sobre o voto correto. Especificamente, a identificação partidária, usada como heurística, aumentou a probabilidade do voto correto em $22 \%$.

Os indivíduos empregam as heurísticas nos julgamentos e na decisão do voto, de forma passiva ou intencional, independentemente do nível de conhecimento e educação (Popkin, 1991; Lupia, 1994; Mondak, 1993), para compensar o baixo nível de informação, a apatia e o desinteresse político (Campbell et al., 1960; Converse, 1964). Para alcançar o voto correto não é diferente, os eleitores adotam a estratégia das heurísticas. Contudo, Lau e Redlawsk (2006) argumentam que esses atalhos cognitivos não beneficiam de forma equânime todos os indivíduos. Aqueles mais bem informados são os mais favorecidos pelo uso dos atalhos cognitivos, sobretudo em cenários políticos 
complexos, com mais de dois candidatos. Os mais bem informados coordenam melhor os atalhos, em especial os de ideologia e identificação partidária.

Poucos estudos e totalmente restritos aos Estados Unidos iniciaram o processo de especificar as possíveis causas para o voto correto a partir de variáveis relacionadas com a comunicação interpessoal (Richey, 2008; McClurg e Sokhey, 2009; Ryan, 2009). Richey (2008) concluiu que as discussões políticas com os líderes de opinião são significativas em relação ao voto correto. Por sua vez, McClurg e Sokhey (2009) encontraram que os especialistas apresentam um efeito marginalmente positivo e que as redes sociais cercadas por conflito de opiniões apresentam um efeito negativo sobre o voto correto. Mais importante, no entanto, é que o resultado da identificação partidária supera o efeito das redes interpessoais. Por fim, Ryan (2009) concluiu que os eleitores sem vínculos partidários são os mais beneficiados pelas conversas entre amigos, familiares e vizinhos. Esses resultados abrem uma perspectiva interessante de pesquisa para os países latino-americanos, particularmente o Brasil, onde há uma baixa identificação partidária.

As pesquisas sobre o voto correto fora do território americano são escassas, com raras exceções, como o trabalho de Walgrave et al. (2009) e o trabalho comparativo de Lau e seus coautores (2014), realizado em 33 países, entre eles o Brasil. O trabalho de Walgrave et al. (2009) utilizou dados da Bélgica, país com problemas institucionais históricos, sistema multipartidário e baixa identificação partidária. A Bélgica é um emaranhado linguístico, o que divide o país em duas regiões basicamente (Flandres, de língua holandesa, e Valônia, de língua francesa). Esse cenário impõe indiscutivelmente dificuldades para que os eleitores belgas alcancem o voto correto em contraste com o cenário institucional dos eleitores norte-americanos.

Os resultados encontrados pelo autor corroboram essa dificuldade, sendo o voto dado na Bélgica extremamente incorreto. Apenas $26 \%$ do eleitorado vota corretamente. Existe possivelmente um problema de mensuração do voto correto, no entanto. Walgrave e os coautores calcularam a intenção de voto, capturada na véspera da eleição, e não o voto dado propriamente. Essa medida pode aumentar o índice do voto incorreto, uma vez que os eleitores tendem na reta final da eleição a mudar de opinião e assim podem alinhar-se corretamente com os seus candidatos.

Em um trabalho comparativo das eleições presidenciais e usando a medida do voto dado, Lau et al. (2014) indicaram que 55\% dos eleitores belgas votaram corretamente na eleição de 2003. Os autores registraram o maior índice de voto correto na Romênia $(89,9 \%)$, no Chile $(89,5 \%)$ e nos Estados Unidos $(88,4 \%)$, enquanto os menores índices registrados estão na Polônia (44\%) e na Holanda (50,3\%). Ainda segundo Lau et al. (2014), o voto correto no Brasil é de $67 \%$ no primeiro turno e de $75,5 \%$ no segundo turno. Os autores também estão interessados nas causas do voto correto, assim eles criaram hipóteses para os mecanismos individuais e institucionais. 
Lau et al. (2014) assumem o aumento da probabilidade do voto correto quando os eleitores são mais sofisticados politicamente, mais experientes e mais motivados. Em outras palavras, os determinantes individuais do voto correto referem-se a um somatório de fatores: conhecimento, nível educacional, relevantes informações armazenadas, familiaridade com as regras do jogo, experiência de vivenciar eleições e, finalmente, a vontade de fazer boas escolhas.

No que concerne aos determinantes institucionais, o pressuposto é de que alguns arcabouços institucionais turvam as escolhas eleitorais e, assim, diminuem as chances do voto correto. Os autores descobriram que o sistema político que promove o voto personalista, e não o partidário, reduz a probabilidade do voto correto. Igualmente, o aumento de alternativas eleitorais - alto número de partidos/candidatos como opção de voto - diminui a possibilidade do voto correto. Em contraste, os autores também encontraram que a distinção ideológica entre esses partidos/candidatos ajuda a mitigar o efeito da quantidade de alternativas eleitorais. Por fim, o aumento da previsão do voto correto é condicionado à disponibilidade de informação política. Quanto mais informações disponíveis, maiores são as chances de o sujeito votar corretamente.

Dando continuidade a essa linha institucional do voto correto, Patel (2011) mostra que o sistema político - proporcional ou majoritário, lista fechada ou aberta - é mais determinante para o voto correto do que as variáveis de nível individual. Em síntese, do conjunto desses resultados, pode-se extrair que as instituições e a informação política são determinantes para o voto correto. Os primeiros trabalhos de Lau e Redlawsk (1997, 2006) indicaram que a identificação partidária exerce nos Estados Unidos uma grande força e que os especialistas empregam melhor os atalhos cognitivos, valendo-se do grau inicial do conhecimento político.

Uma vez que já sabemos a definição conceitual do voto correto e que a ação de votar corretamente é condicionada por certos fatores institucionais e pelo processo informativo, cabe apontar aqui alguns entraves para alcançar o voto correto no Brasil e possivelmente em outros países da América Latina. Devido ao histórico social e político, algumas limitações são mais evidentes: 1) os eleitores variavelmente apresentam problemas na aquisição de informação, com uma distribuição enviesada da informação; 2) o sistema político é complexo, com fragmentação dos partidos, baixa identificação partidária e ideológica; 3) o sistema eleitoral brasileiro é de representação proporcional de lista aberta, que estimula o voto nos candidatos e gera competição intrapartidária; 4) as eleições são sempre povoadas por muitos candidatos, limitando a aquisição de informações e dificultando a decisão do voto; 5) em certas campanhas não existe distinção entre as propostas dos candidatos. Quando não há polarização entre as propostas torna-se mais difícil ao eleitor distinguir o que combina mais com o seu interesse eleitoral; 6) os recursos de campanha não são distribuídos de maneira equânime, de modo que certos candidatos têm mais chances de aparecer publicamente do que outros. 
Os estudos do voto correto incluem as democracias estabelecidas. Não há análises sistemáticas do voto correto nas jovens democracias ${ }^{1}$. Assim, proponho uma análise para substituir os canais de informação institucionalizados pelos canais informais nas novas democracias. As conversas interpessoais sobre política funcionam como atalhos informativos e cognitivos, substituindo os partidos políticos e outros mecanismos institucionais. Essas interações sociais são mecanismos de disseminação de informação e contribuem para o aumento do nível informativo devido ao seu baixo custo e ao grau de confiança intraindividual, aumentando a probabilidade do voto correto no Brasil.

Entretanto, os atalhos informativos não devem ser vistos como uma panaceia. $\mathrm{O}$ acesso às fontes de informação não é igualitário a todos os cidadãos, o que provoca desigualdade informacional e gera entraves para as decisões de qualidade (Carpini e Keeter, 1997; Rennó, 2007; Lau e Redlawsk, 2001). Por esse motivo é provável encontrarmos diferença entre os mais bem informados e os menos bem informados em relação ao voto correto. A importância dos atalhos cognitivos para uma escolha política acertada permanece, mas o ponto de largada dos eleitores em termos de informação também importa. A premissa colocada é de que o acúmulo de informação ajuda a melhorar a competência do cidadão, que passa a articular os interesses, preferências e valores com a decisão do voto de forma mais transparente e direta.

\section{Redes interpessoais}

As eleições seguem por uma lógica social, visto que é o espaço das trocas de informações e das deliberações públicas, bem como da persuasão política. As pessoas tentam se influenciar mutuamente para fazer algo que elas gostariam, demonstrando poder e liderança (Dahl, 1957; McClurg e Young, 2010). A regra é que os indivíduos mais interessados exerçam uma grande influência sobre outras pessoas menos interessadas (Huckfeldt e Sprague, 1995). Esse comportamento abre espaço para a seguinte pergunta: as relações interdependentes restringem ou ampliam as chances do cidadão de fazer escolhas eleitorais esclarecidas, que vão ao encontro das preferências políticas e ideológicas?

A resposta é que ambos os padrões de comportamento podem ocorrer, dependendo das características das relações interpessoais. Os atributos de rede e do contexto social, centrais para essa análise, são os de conflito e diversidade ${ }^{2}$. 0 atributo de conflito é determinado quando a opinião do principal entrevistado (ego) é expressamente diferente das preferências dos outros membros da mesma rede social

\footnotetext{
${ }^{1} \mathrm{O}$ trabalho de Lau et al. (2014) é o único que inclui países da América do Sul (Brasil, Chile e Peru), mas a análise não testa as variáveis relacionadas com o meio social e não há uma sistematização ou um aprofundamento desses resultados para os países considerados como novas democracias.

2 Alguns autores empregam heterogeneidade; outros mencionam diversidade. Uso o termo diversidade por representar melhor o conceito desejado, que é o de variedade, qualidade dos diversos ou multiplicidade.
} 


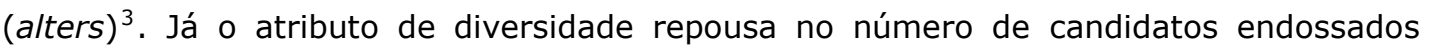
pelos membros da rede, surgindo uma variedade de preferências dentro da rede social.

$\mathrm{O}$ atributo de conflito dentro da rede ou do contexto social tende a restringir as interações sociais, pois as pessoas geralmente silenciam e não se envolvem em polêmicas, evitando algum tipo de estresse psicológico. Em contraste, o atributo de diversidade tende a ampliar o fluxo de informação dentro da rede e do contexto social. Assim, argumento que o atributo de conflito reduz as chances do voto correto e, por sua vez, o atributo de diversidade aumenta as oportunidades para o cidadão votar corretamente.

Nesse sentido, as relações interpessoais estabelecem, minimamente, duas formas: a divergência de preferências da pessoa de referência (ego) com os membros da rede, dada a mesma rede social (conflito), e a soma das preferências que existem dentro da rede, independentemente se há concordância ou não das opiniões entre os parceiros sociais que compõem a rede social (diversidade).

A origem desse debate está na teoria econômica da decisão do voto, em que Downs (1957) postula que os indivíduos buscam informações através dos especialistas dos seus imediatos círculos sociais, pois oferecem opiniões similares, reduzindo os custos e o tempo para obter informação. Ampliando os termos desse debate, Granovetter (1973) promove a ideia dos laços fracos ${ }^{4}$, segundo a qual as informações mais novas e não redundantes estão disponíveis com os contatos menos frequentes - os amigos dos amigos. As relações sociais não são coesas ou diretas, argumenta o autor.

Essas primeiras formulações, atinentes aos grupos coesos e laços fracos, sustentaram as formulações teóricas subsequentes, principalmente a partir da década de 1990. Destaca-se nesse debate a discussão sobre os ambientes em que as pessoas estão inseridas e o atributo de conflito.

Mutz (1998) e Mutz e Martin (2001) assinalam que os cidadãos cultivam relações homogêneas, evitando a exposição de opiniões conflituosas, no entanto, cada vez mais opiniões contrárias a essa definição são audíveis (Huckfeldt, Johnson e Sprague, 2002, 2004). Para esses autores, o conflito é resultante da própria estrutura social e persiste mesmo entre os parceiros sociais mais próximos, como os familiares. Isso porque os cidadãos não têm controle irrestrito sobre o fluxo de informação, logo as opiniões de conflito não podem ser evitadas totalmente. O conflito de opiniões políticas é sustentado pela própria natureza da democracia e, particularmente, pelo convívio social (Huckfeldt e Sprague, 1995).

O dilema aprofunda-se com a ampliação desse debate. Por um lado, Mutz (2002a) afirma que a exposição a opiniões de conflito contribui para o aumento da

\footnotetext{
${ }^{3}$ Essa técnica é conhecida como egocentric network porque consiste em um ego (principal respondente) e um conjunto de alters (parceiros sociais nomeados pelo ego), estabelecendo um diagrama com a parte central de um eixo e várias linhas que unem aos indivíduos da extremidade.

${ }^{4}$ Ver Burt (1992) para um aprofundamento empírico da ideia dos laços fracos a partir da tese do structural holes.
} 
tolerância e da legitimidade dos argumentos. Por outro lado, Mutz (2002b) e Mutz e Mondak (2006) assinalam que um ambiente de discordância política gera atitudes ambivalentes e ansiedades, dois componentes psicológicos que diminuem o ímpeto pela participação política. Ainda no campo da associação entre relações sociais e participação política, Klofstad $(2007,2009)$ assegura que os estudantes que discutem civicamente com os companheiros de quarto são recrutados mais facilmente a participar das atividades cívicas.

Os resultados díspares entre os trabalhos de Mutz e Klofstad são explicados pelo ambiente em que se dá a relação entre os indivíduos. Enquanto o estudo de Klofstad ocorre em um ambiente homogêneo (companheiros de quarto), no qual os conflitos não são ordinários, Mutz analisa os indivíduos em um ambiente heterogêneo (local de trabalho) carregado de conflito. A composição social das análises, homogênea ou heterogênea, é vital para responder a esses achados discrepantes.

Os trabalhos consequentes tentaram revisitar esses resultados, buscando colocar ordem no debate. Desse modo, Klofstad, Sokhey e McClurg (2013) defendem que diferentes medidas do atributo de conflito apresentam distintos efeitos. Huckfeldt, Johnson e Sprague (2004) mensuram o atributo de conflito pelo grau de discordância da preferência eleitoral entre o principal respondente (ego) e os demais membros da rede social (alters). Diferentemente, Mutz (2006) avalia a percepção do nível de conflito entre os parceiros sociais, valendo-se de uma combinação de dados de opinião pública sobre percepção.

A partir dessa base teórica, este artigo adota a estratégia de Huckfeldt, Johnson e Sprague (2004), isto é, mensura o conflito dentro de rede e contexto social pela discordância na preferência de voto do principal respondente (ego) e dos seus parceiros sociais (alters). A principal vantagem consiste no cálculo da variável "conflito", baseado na comparação das preferências eleitorais dos cidadãos que compõem a rede social, e não na percepção do indivíduo quanto à discordância de opiniões.

No entanto, o atributo de conflito não é exaustivo, sobretudo em um sistema multipartidário, como é o caso do Brasil, onde é possível observar múltiplas preferências sem constatar nenhum tipo de conflito. Alguns poucos pesquisadores começaram a olhar para esse tipo de distribuição das preferências políticas, criando uma medida de diversidade de opiniões. Em análises anteriores, os pesquisadores comparavam as preferências divergentes do principal entrevistado (ego) com a dos membros da rede. Agora, o foco é analisar o número total de candidatos apoiados pelos parceiros sociais dados a mesma rede e o mesmo contexto social.

Os trabalhos de $\mathrm{Nir}(2005,2011)$ são os primeiros a separar por níveis a estrutura da rede social. Levando em consideração dois grupos distintos, de concorrência e de oposição, a autora afirma que a concorrência é favorável à participação e a oposição apresenta um efeito negativo sobre a participação. Nir (2011) refere-se à concorrência como uma variável formada por um conjunto de opiniões divergentes e convergentes 
entre os vários membros da rede. Por oposição, diferentemente, a autora refere-se à discordância de preferências entre o principal respondente (ego) e os demais parceiros sociais (alters). Em outros termos, concorrência é uma medida análoga ao atributo de diversidade e oposição significa o atributo de conflito.

Usando a mesma linha de argumentação, isto é, usando dois níveis para redes sociais, Baker, Ames e Rennó (2006) testam os impactos do atributo de conflito e do ambiente heterogêneo, cujas características conceituais e metodológicas se assemelham ao atributo de diversidade. Os autores encontraram que a mudança de voto aumentou substancialmente quando os eleitores conversavam com os parceiros sociais de vozes discordantes (conflito), em especial quando essas discussões eram com os vizinhos.

Essa literatura tem algumas lacunas. Por exemplo, os estudos de interação interdependente raramente separam os conceitos de rede e contexto social. Essa separação, no entanto, é importante porque as redes interpessoais não são uma tradução direta dos contextos, embora estejam intimamente conectadas. A próxima seção é dedicada a esclarecer a diferença entre redes e contexto social.

\section{Contexto social}

Huckfeldt e Sprague (1995) afirmam que as redes são formadas pelas interações sociais dos indivíduos, que, por sua vez, estão localizados dentro de ambientes sociais e políticos. As características dos contextos - político, social, tempo e espacial - podem ter impacto na formação das redes sociais, oferecendo oportunidades ou restrições de interações (Huckfeldt, 1983, 2007). Como consequência, a disponibilidade de informação também sofre alterações.

Na perspectiva da distribuição de informação, Huckfeldt e Sprague apontaram o papel do contexto social como "fatores extraindividuais" (1995, p. 10). Particularmente, os autores olharam para os efeitos dos ambientes em que os indivíduos estão inseridos. Esse ponto de vista propõe que não somente as relações interdependentes importam, mas também o contexto social condiciona o nível de informação das pessoas. Como o comportamento humano é ligado intrinsecamente à informação obtida, as distintas estruturas de rede e de contexto social afetam provavelmente o comportamento político, ou seja, o voto correto.

Alguns estudiosos já argumentaram no sentido de que o contexto social em que os indivíduos estão inseridos desempenha um relevante papel para explicar o comportamento político. Por exemplo, Putnam (1966) sugere que a comunidade, então intermediada pela socialização dos membros de grupos, modela as atitudes para a identificação partidária. Do mesmo modo, combinando dados de amostra e dados censitários agregados, Huckfeldt (1979) encontra evidências de que a participação política é menos ou mais incentivada dependendo das características sociais do bairro em que as pessoas vivem. Usando medidas de comunidade e de bairro, Mackuen e Brown 
(1987) descobrem implicações robustas sobre a mudança de intenção de voto através do contexto político, dando forma às opiniões e atitudes. O impacto do contexto social opera no processamento de informação através de uma "comunicação quente" entre vizinhos e amigos.

No entanto, a literatura recente ignora esses efeitos, em especial quando considera as análises a respeito das novas democracias. É necessário, ainda, testar algumas especificidades do contexto social, como os diferentes atributos que o compõem, a exemplo do que é feito para o nível da rede social. Além disso, o estudo de contexto social rivaliza com a ideia de que os cidadãos estão cada vez mais insulados.

O pensamento moderno acredita que os cidadãos são átomos isolados. Putnam (2000) aponta para a expansão urbana e a falta de socialização nos bairros como causas possíveis para o declínio da participação, da confiança e da cooperação entre cidadãos. 0 avanço tecnológico e das comunicações, principalmente o advento da internet, reforça a impressão de falta de conectividade social entre as pessoas. Ademais, existe a sensação de insegurança que inibe as relações sociais, e a realidade de migração habitacional, já que os indivíduos moram cada vez mais longe do centro das cidades devido ao alto custo dessa região.

Por outro lado, BayBeck e McClurg (2005) avaliam esses aspectos mencionados por Putnam e constatam que o ambiente social em que as pessoas vivem ainda influencia as atitudes humanas. Igualmente, Baker, Ames e Rennó (2006) testam o impacto do contexto social e confirmam o efeito positivo sobre a volatilidade eleitoral. Os resultados apontaram que as discussões de conflito dentro dos bairros aumentaram as chances de volatilidade eleitoral.

Este artigo busca resgatar o elo do contexto social com os diferentes padrões de atitude política, de modo a ampliar as explicações do voto correto para além dos fatores individuais. Ainda, considera o contexto social em dois níveis: os atributos de diversidade e de conflito. Esse tipo de análise introduz um novo elemento ao debate sobre contexto social e voto correto.

\section{Hipóteses}

A primeira hipótese é: o número de candidatos importa para o voto correto, sob o argumento de que o voto correto tende a ser maior no segundo turno da eleição presidencial. Em cenários menos complexos, com apenas dois candidatos, e com o aprendizado político do primeiro turno, a tendência é o aumento do voto correto. A segunda hipótese é: há diferença entre os mais bem informados e os menos bem informados em relação ao voto correto para o primeiro e o segundo turno, em uma referência à importância da informação para o voto correto. As demais hipóteses, que tratam especificamente dos atributos das redes e do contexto social, são combinadas para o primeiro e o segundo turno das eleições. 
H1: A chance de ocorrência do voto correto é maior no segundo turno do que no primeiro, porque há menos candidatos e a diferença entre eles tende a ficar mais clara.

H2: O voto correto é mais frequente entre os eleitores mais bem informados do que entre aqueles menos bem informados, porém esse resultado deve ser mais forte no primeiro turno.

H3: O atributo de conflito deve gerar uma relação negativa com o voto correto. Isso porque o conflito de opiniões dentro da rede social produz ambivalências e incertezas, e reduz as interações sociais.

H4: O atributo de diversidade deve produzir uma relação positiva com o voto correto. Quanto maior a diversidade de preferências, maior a variedade de informações a que os indivíduos são expostos. A divergência de preferências políticas estimula as discussões sobre política, favorecendo o voto correto.

H5: A medida Bairro Conflito deve estabelecer uma relação negativa com o voto correto por sua capacidade de expor os moradores a visões políticas conflituosas.

H6: A medida Bairro Diversidade deve produzir uma relação positiva com o voto correto. A diversidade de opiniões dentro do bairro pode ser usada como atalhos informativos, estabelecendo uma direção positiva com o voto correto.

\section{Desenho de pesquisa, dados e método}

Este artigo usa informações primárias de opinião pública, cujos dados foram coletados em duas cidades brasileiras, Juiz de Fora (MG) e Caxias do Sul (RS) (Ames, Baker e Rennó, 2002). Essas cidades de médio porte favorecem um exame mais detalhado do comportamento do que uma amostra nacional convencional, porém perdese em termos de validade externa. Juiz de Fora e Caxias do Sul apresentam diferenças de ideologia e organização partidária. Por outro lado, as duas cidades oferecem similaridades por raça, gênero, educação e tamanho do eleitorado. Ao passo que em Caxias do Sul existe uma forte polarização entre o PT e o PMDB e uma tendência a favor do PSDB em termos nacionais, em Juiz de Fora os partidos tendem a ser organizados de forma frágil e os eleitores apoiaram fortemente Lula em 2002 e 2006.

Esse estudo desenvolve-se por uma observação transversal nos dados oriundos de uma pesquisa de painel $^{5}$ para três momentos distintos da campanha presidencial de

\footnotetext{
${ }^{5} \mathrm{O}$ banco de dados foi transformado para o formato wide, por isso o modelo multinível, também conhecido como "modelo hierárquico linear", foi substituído pelo modelo probit.
} 
2002. A primeira onda de entrevistas foi realizada em abril a fim de obter um ponto de referência de informação dos entrevistados. O segundo ciclo de entrevistas foi realizado em agosto, quando iniciou o Horário Gratuito de Propaganda Eleitoral (HGPE). Por fim, o terceiro ciclo se deu em outubro de 2002, entre o primeiro e o segundo turno das eleições. O estudo entrevistou 6.970 pessoas, divididas igualmente entre Juiz de Fora e Caxias do Sul. Para a finalidade deste artigo, trabalhamos somente com os quatro principais candidatos da eleição de 2002 - Serra, Lula, Ciro Gomes e Garotinho.

Os entrevistados foram selecionados por meio da técnica de amostragem em múltiplos estágios, com seleção aleatória em cada um dos quatro estágios: bairro, setores censitários, domicílios e respondentes. Para as duas cidades analisadas, 20 bairros foram selecionados aleatoriamente. Dentro de cada bairro, de dois a dez setores censitários foram selecionados, sendo que cada setor censitário contém cerca de 200 domicílios. Os respondentes, por sua vez, foram selecionados a cada seis residências e dentro de cada casa o respondente foi escolhido de acordo com a proximidade do aniversário. Para obter as substituições dos entrevistados para as ondas 2 e 3, decidiu-se voltar à última residência da onda anterior e recomeçar então o procedimento das entrevistas a cada seis casas (Baker, Ames e Rennó, 2006).

Quanto à construção da variável independente "rede social", a série de entrevistas incluiu perguntas sobre como os eleitores discutem a política com vizinhos, amigos e familiares. Assim, os entrevistados foram solicitados a indicar até três parceiros sociais com quem mais conversam sobre política, caracterizando o processo de snowball. Metodologicamente, usou-se apenas a terceira onda (outubro) para construir as variáveis independentes por se considerar que a proximidade da eleição potencializa os atributos de interesse da pesquisa, tanto para a rede social como para o contexto social.

$\mathrm{O}$ atributo de conflito, que visa entender os efeitos de opiniões conflitantes dentro da própria rede, foi constituído pela comparação da preferência eleitoral do principal entrevistado (ego) com as preferências dos demais debatedores sociais. Por sua vez, o atributo de diversidade foi composto pelo número de candidatos presidenciais representados na rede social.

A diferença empírica entre o atributo de conflito e o de diversidade está na forma da construção dessas variáveis. Enquanto o atributo de conflito é calculado pela comparação do voto dado entre o principal entrevistado (ego) e os seus principais parceiros sociais (alters), o atributo de diversidade é o somatório do voto dado de todos os membros sociais, formando uma medida de variedade das preferências políticas.

Para a variável "contexto social", usou-se o bairro como medida central e, assim como para a rede social, os atributos de conflito e diversidade foram aplicados. A variável "bairro conflito" foi medida pela parcela dos residentes do bairro (alters) que apresentaram opinião conflituosa em relação à do principal respondente (ego). Já a variável "bairro diversidade" foi medida pela preferência do voto de cada principal respondente (ego) dos bairros. Quanto mais candidatos apoiados, maior o índice de 
diversidade.

A variável dependente é formada pelas perguntas atinentes a preferências políticas (reforma agrária, gastos sociais, ideologia e privatizações), identificação com os grupos sociais (Central Única dos Trabalhadores, Movimento dos Sem Terra, empresários e evangélicos), identificação partidária e imagem dos candidatos. Os entrevistados foram solicitados a dizer quão favoráveis ou contrários eram quanto a privatização, gastos sociais e reforma agrária, e em relação aos grupos sociais em destaque, por exemplo. Em seguida, os entrevistados avaliavam, de acordo com as percepções individuais, a posição política dos candidatos referente a essas mesmas perguntas. Em caso de convergência e o voto dado ter sido para o candidato com o maior número de pontos de convergência, assume-se o voto como correto.

Essa técnica para construir a variável "voto correto" impõe cuidados, como o risco de projeção dos eleitores. O problema de projeção centra-se quando os eleitores pensam que os candidatos de que eles gostam estão próximos e os candidatos de que eles não gostam estão distantes. Por exemplo, o indivíduo assume o posicionamento político do candidato sobre a reforma agrária por uma decisão eleitoral, que não é necessariamente a real posição política do candidato no tema político em destaque.

O modelo probit, conhecido como um modelo de probabilidade, foi o método utilizado para analisar as chances de ocorrência do voto correto (variável binária) a partir das variáveis independentes dessa amostra. Em modelos de probabilidade é comum o uso do efeito marginal, funções não lineares das estimativas dos parâmetros, previsto para a associação das mudanças da variável dependente sobre as variáveis preditoras (Lima, 1996).

\section{Operacionalização do voto correto no Brasil}

O procedimento adotado para o voto correto no Brasil segue, sempre que possível, as técnicas originais de Lau e Redlawsk. No entanto, houve a necessidade de fazer alguns ajustes. No questionário brasileiro não há perguntas que meçam o grau de importância dos temas políticos sob o ponto de vista pessoal dos respondentes. Dessa maneira, a única opção foi retirar essa variável das nossas análises. Em resumo, o desenho da pesquisa foi reduzido a dois eixos: a) as preferências políticas dos eleitores; b) a posição política dos candidatos.

O eixo 1 (preferências políticas dos eleitores) é definido pelas seguintes categorias: identificação partidária, questões políticas, identificação com os grupos sociais e personalidade dos candidatos. A seguir, cada item é descrito.

Identificação/Simpatia partidária: A pergunta sobre esse tema refere-se a simpatia, e não a identificação, como no caso norte-americano. A cada combinação positiva entre a 
resposta do entrevistado e o partido dos candidatos, considerou-se +1 e para as demais situações -1 . Como sabemos a filiação dos políticos, essa variável é simplesmente uma contagem direta entre a resposta do respondente e a realidade.

Questões políticas: Os temas tratados foram privatização, gastos sociais, ideologia e reforma agrária, e perguntou-se sobre o autoposicionamento dos entrevistados e suas percepções quanto à posição dos candidatos a presidente. A estimativa dessa variável é dada pela comparação entre a posição dos candidatos e a dos eleitores. Quando candidato e eleitor estiverem no mesmo lado político, atribui-se +1 , e nas demais situações -1 . Cada pergunta equivale a um item no sumário final de avaliação.

Conexões com grupos sociais/políticos: Em uma escala de 0 a 10 - em que 0 quer dizer que a pessoa não gosta nada do grupo e 10 indica que a pessoa gosta muito do grupo -, os entrevistados responderam quão bem se sentem em relação à Central Única dos Trabalhadores (CUT), ao Movimento dos Sem Terra (MST), aos evangélicos, empresários e negros. Para todas as respostas acima da média (5), considerou-se 1, e abaixo da média, 0. Após essa primeira codificação, testou-se a correlação tetracórica por ser mais fácil de visualizar a direção das opiniões com mais de duas opções. Para cada combinação significativa, classificou-se como +1 ; do contrário -1 .

Personalidade do candidato: Esse item é medido da mesma forma como previsto no modelo de Lau e Redlawsk, assim, a resposta máxima dentro da escala significa +1 , enquanto a resposta negativa representa -1 . As características incluídas são inteligência, honestidade, solidariedade e determinação.

Por sua vez, o eixo 2 (informações do posicionamento dos candidatos) é um item que tenta capturar a opinião dos respondentes a respeito da posição política dos candidatos. As perguntas que compõem esse eixo referem-se a privatização, gastos com os programas sociais, reforma agrária e sentimentos em relação aos candidatos. Nota-se também que existem perguntas de autoposicionamento sobre esses temas, o que permite saber se os candidatos e os eleitores compartilham de pensamentos políticos similares. Se ambos estiverem no mesmo lado político, a variação é de +1 e, se não estiverem, a variação é de -1 .

Para o sumário final de avaliação, somaram-se todos os scores de cada candidato, os empates foram eliminados e tirou-se a média. O empate ocorre quando mais de um candidato recebe a mesma pontuação, algo que aconteceu para o caso do Brasil por se tratar de quatro candidatos em disputa. O candidato com a maior avaliação, ou pontuação, deveria ter sido o escolhido pelo respondente/eleitor para caracterizar o voto correto. A avaliação do voto correto no Brasil é, em síntese, a comparação das 
preferências políticas dos eleitores com as posições dos candidatos. Em caso de convergência, o voto correto é computado.

\section{Resultados}

A Tabela 1 mostra o índice de voto correto para o primeiro e o segundo turnos das eleições brasileiras de 2002 em Juiz de Fora e Caxias do Sul. Como esperado, o voto correto é maior no segundo turno do que no primeiro. O motivo muito provavelmente está relacionado com a quantidade de candidatos e, por extensão, com a clareza e a disponibilidade de informação. Apesar da construção do voto correto no Brasil não seguir exatamente os mesmos critérios de Lau e Redlawsk, chegamos ao mesmo resultado (67\%) com o estudo comparativo de Lau et al. (2014).

Tabela 1

Índice de voto correto para o primeiro e segundo turnos das eleições brasileiras de 2002 (\%)

\begin{tabular}{|l|c|}
\hline Eleição & Voto correto \\
\hline $1^{\circ}$ Turno & 67,66 \\
\hline $2^{\circ}$ Turno & 80,44 \\
\hline
\end{tabular}

Fonte: Pesquisa eleitoral em duas cidades brasileiras, Universidade de Pittsburgh/National Science Foundation, 2002.

Um dos objetivos específicos deste artigo é testar se há diferença entre os mais bem informados e os menos bem informados quanto ao voto correto. Para essa análise, usamos o teste não paramétrico Wilcoxon rank-sum, correspondente ao teste $t$ (Field, 2009). Esse teste é usado quando a variável dependente não apresenta uma distribuição normal, como é o caso específico. A lógica por trás do teste Wilcoxon rank-sum é que não existe diferença entre os grupos quando são encontrados valores iguais para as categorias de cada grupo. Conforme esperado, porém, o resultado encontrado sugere que a diferença entre os grupos é estatisticamente significativa ( $z=-3.426, p=0,0006)$. Os mais bem informados votam corretamente com mais frequência do que os menos bem informados no primeiro turno, o que pode ser confirmado quando comparamos os valores do rank-sum (menos bem informado $=2020120,5$; mais bem informado $=$ $4537510,5)$. A soma dos valores para os mais bem informados é maior do que a soma dos valores para os menos bem informados. 
Tabela 2

Teste Wilcoxon rank-sum. Informação e voto correto para o primeiro turno

\begin{tabular}{|l|c|c|c|}
\hline & Observação & Rank-sum & Esperado \\
\hline Menos bem informados & 1171 & 2020120,5 & 2120681 \\
\hline Mais bem informados & 2450 & 4537510,5 & 4436950 \\
\hline Combinado & 3621 & 6557631 & 6557631 \\
\hline
\end{tabular}

Fonte: Pesquisa eleitoral em duas cidades brasileiras, Universidade de Pittsburgh/National Science Foundation, 2002.

Essa tendência permanece para o segundo turno, no entanto, esse efeito é marginal, como se observa na Tabela 3 ( $z=-1.660 ; p=0,09)$. Explica-se esse resultado com base em Lau e Redlawsk (2001): os mais bem informados empregam melhor os atalhos informativos do que os menos bem informados em cenários complexos, quando há mais de dois candidatos. Portanto, assume-se que a vantagem dos mais bem informados sobre os menos bem informados diminui à medida que o cenário se torna menos complexo, como é o caso do segundo turno das eleições. Com apenas dois candidatos, situação em que as diferenças políticas são mais concretas, é mais fácil para qualquer cidadão associar suas preferências com a posição dos candidatos.

Tabela 3

Teste Wilcoxon rank-sum. Informação e voto correto para o segundo turno

\begin{tabular}{|l|c|c|c|}
\hline & Observação & Rank-sum & Esperado \\
\hline Menos bem informados & 444 & 483681,5 & 504162 \\
\hline Mais bem informados & 1826 & 2093903,5 & 2073423 \\
\hline Combinado & 2270 & 2577585 & 2577585 \\
\hline
\end{tabular}

Fonte: Pesquisa eleitoral em duas cidades brasileiras, Universidade de Pittsburgh/National Science Foundation, 2002.

A Tabela 4 apresenta os resultados preditos pelo modelo probit e estimados pelo efeito marginal a fim de explicar a probabilidade de ocorrência. Os testes foram feitos da seguinte maneira: no modelo 1 , todas as variáveis foram testadas juntas; no modelo 2 , 0 teste foi feito somente com as variáveis independentes de rede social. As variáveis de contexto foram retiradas do modelo.

Para o modelo 1, as hipóteses sobre os atributos da rede social são confirmadas parcialmente. Ao passo que a variável "diversidade social" não é estatisticamente significativa, a variável "conflito de opiniões" apresentou um efeito significativo, porém marginal. À medida que aumenta o conflito de opiniões dentro da rede social, menor é a expectativa do voto correto. As hipóteses acerca do contexto social, referentes a diversidade e conflito de opiniões dentro do bairro, apresentam confirmações mais 
robustas e, principalmente, na direção preconizada. A diversidade de opiniões no bairro aumenta as chances do voto correto, enquanto o conflito de opiniões dentro do bairro reduz as chances do voto correto.

Em relação à probabilidade de ocorrência do voto correto por essas variáveis independentes, o resultado é o seguinte: o conflito de opiniões dentro da rede social reduz em $3,7 \%$ as chances de o cidadão votar corretamente. Isso implica dizer que quanto maior o conflito de opiniões entre o principal respondente e os demais parceiros sociais, o voto correto tem aproximadamente três vezes menos chances de ocorrer. Da mesma forma, o conflito de opinião dentro do bairro reduz a possibilidade do voto correto em $41,5 \%$. Por outro lado, a diversidade de opiniões dentro do bairro aumenta em $7,7 \%$ a probabilidade do voto correto. A diversidade de opinião para rede social, em relação à qual se esperava encontrar um efeito positivo sobre a variável dependente, não opera significativamente.

Algumas variáveis de controle apresentaram efeitos significativos, como: informação política, mulher e evangélico. Conforme a lógica aponta, a informação política ajuda o cidadão a escolher o candidato correto de acordo com os valores e interesses políticos dados. Assim, a informação aumenta em $10,6 \%$ as chances do voto correto. A religião também foi aferida nesse modelo. O voto evangélico é $12,8 \%$ mais provável de ser correto do que o voto dos católicos, dos não religiosos e de outras religiões. Por fim, ser mulher aumenta a probabilidade de votar corretamente em quase $8 \%$.

No modelo 2, no qual as variáveis de contexto são retiradas, o coeficiente da variável "conflito" aumenta. Assim, o conflito de opinião dentro da rede social passa a reduzir a probabilidade de ocorrência do voto correto em $9 \%$ aproximadamente. Outro dado que merece uma menção diz respeito ao atributo de diversidade, embora não apresente um efeito significativo. A direção do sinal, como é possível observar, muda quando as variáveis de contexto são retiradas do modelo. As variáveis de contexto estavam atenuando o efeito de rede social. As demais variáveis não têm mudanças representativas, salvo a variável "religião" que perde o efeito no modelo 2. 
Tabela 4

Modelo de Probit robusto para avaliar o voto correto do primeiro turno na eleição de 2002, por redes sociais e contexto social

\begin{tabular}{|c|c|c|c|c|}
\hline \multirow[b]{2}{*}{$\begin{array}{l}\text { Variáveis } \\
\text { independentes }\end{array}$} & \multicolumn{2}{|c|}{$\begin{array}{c}\text { Modelo } 1 \\
\text { (preferido) }\end{array}$} & \multicolumn{2}{|c|}{ Modelo 2} \\
\hline & Coef. & Prob. & Coef. & Prob. \\
\hline $\begin{array}{l}\text { Redes sociais } \\
\text { Diversidade de opiniões }\end{array}$ & $\begin{array}{l}-0,027 \\
(0,066)\end{array}$ & $-0,010$ & $\begin{array}{c}0,031 \\
(0,065)\end{array}$ & 0,011 \\
\hline Conflito de opiniões & $\begin{array}{c}-0,100+ \\
(0,060)\end{array}$ & $-0,037$ & $\begin{array}{c}-0,243 * * * \\
(0,055)\end{array}$ & $-0,090$ \\
\hline $\begin{array}{l}\text { Contexto social } \\
\text { Bairro - Diversidade de } \\
\text { opiniões }\end{array}$ & $\begin{array}{l}0,210^{*} \\
(0,097)\end{array}$ & 0,077 & & \\
\hline $\begin{array}{l}\text { Bairro - Conflito de } \\
\text { opiniões }\end{array}$ & $\begin{array}{c}-1,120 * * * \\
(0,097)\end{array}$ & $-0,415$ & & \\
\hline $\begin{array}{l}\text { Controle } \\
\text { Informação política }\end{array}$ & $\begin{array}{l}0,288+ \\
(0,159)\end{array}$ & 0,106 & $\begin{array}{l}0,264+ \\
(0,158)\end{array}$ & 0,098 \\
\hline $\begin{array}{l}\text { Atenção à campanha } \\
\text { política }\end{array}$ & $\begin{array}{c}0,012 \\
(0,033)\end{array}$ & 0,004 & $\begin{array}{c}0,021 \\
(0,033)\end{array}$ & 0,007 \\
\hline Atenção à televisão & $\begin{array}{l}-0,082 \\
(0,122)\end{array}$ & $-0,030$ & $\begin{array}{l}-0,087 \\
(0,121)\end{array}$ & $-0,032$ \\
\hline Atenção ao jornal & $\begin{array}{l}-0,059 \\
(0,112)\end{array}$ & $-0,022$ & $\begin{array}{l}-0,053 \\
(0,109)\end{array}$ & $-0,019$ \\
\hline Mulher & $\begin{array}{l}0,212 * * \\
(0,077)\end{array}$ & 0,079 & $\begin{array}{l}0,197 * * \\
(0,076)\end{array}$ & $-0,073$ \\
\hline Branco & $\begin{array}{l}-0,071 \\
(0,079)\end{array}$ & $-0,026$ & $\begin{array}{l}-0,088 \\
(0,077)\end{array}$ & $-0,032$ \\
\hline Educação & $\begin{array}{c}0,050 \\
(0,046)\end{array}$ & 0,018 & $\begin{array}{c}0,052 \\
(0,046)\end{array}$ & 0,019 \\
\hline Renda & $\begin{array}{c}0,000 \\
(0,000)\end{array}$ & $-0,000$ & $\begin{array}{c}0,000 \\
(0,000)\end{array}$ & 0,000 \\
\hline Idade & $\begin{array}{c}0,000 \\
(0,002)\end{array}$ & $-0,000$ & $\begin{array}{l}-0,001 \\
(0,002)\end{array}$ & $-0,000$ \\
\hline Evangélico & $\begin{array}{l}0,370 * * \\
(0,116)\end{array}$ & 0,128 & $\begin{array}{c}0,176 \\
(0,112)\end{array}$ & 0,063 \\
\hline Constant & $\begin{array}{c}0,227 \\
(0,290) \\
\end{array}$ & & $\begin{array}{c}0,177 \\
(0,194)\end{array}$ & \\
\hline Pseudo R & 0,048 & & 0,025 & \\
\hline McFadden's $\mathrm{R}^{2}$ & 0,049 & & 0,025 & \\
\hline $\mathrm{N}$ & 1.327 & & 1.327 & \\
\hline
\end{tabular}

Fonte: Pesquisa eleitoral em duas cidades brasileiras, Universidade de Pittsburgh/National Science Foundation, 2002.

Significância: $+p<0,10, * p<0,05, * * p<0,01, * * * p<0,001$.

Nota: Os valores da tabela são resultados de uma regressão probit robusta. Entre parênteses estão os erros-padrão. Na última coluna estão os resultados probabilísticos do efeito marginal das variáveis independentes sobre o voto correto. 
Voto correto presidencial, segundo turno

Para o modelo do voto correto do segundo turno, optou-se também por uma regressão probit e o efeito marginal para relatar os resultados encontrados. As hipóteses testadas são as mesmas, não há razão teórica para mudar a direção delas. Como se observa na Tabela 5, especificamente para o modelo 1 , os resultados indicam que somente a variável "conflito bairro" tem efeito estatisticamente significativo sobre o voto correto. As chances de o indivíduo votar corretamente são reduzidas em aproximadamente $27 \%$ quando há opiniões de conflito dentro do bairro. Encontrou-se, também, um efeito marginal da variável "cor" sobre o voto correto. Os brancos têm $4,7 \%$ mais chances de votar corretamente do que os não brancos.

No modelo 2, quando se retiram as variáveis independentes de contexto social, evidenciam-se os efeitos das variáveis de rede social. A diversidade de opinião aumenta em 3,8\% a probabilidade de ocorrência do voto correto, enquanto o conflito de opiniões restringe as chances do voto correto em 6,6\%. Esses dois atributos de rede social apresentam os seus efeitos na direção preconizada pelas hipóteses. Ademais, o efeito de ser evangélico opera negativamente sobre o voto correto do segundo turno, reduzindo as chances deste em quase $7 \%$.

Tabela 5

Modelo de probit robusto para avaliar o voto correto do segundo turno na eleição de 2002, por redes sociais e contexto social

\begin{tabular}{|l|c|c|c|c|}
\hline & \multicolumn{2}{|c|}{$\begin{array}{c}\text { Modelo 1 } \\
\text { (preferido) }\end{array}$} & \multicolumn{2}{c|}{ Modelo 2 } \\
\hline $\begin{array}{l}\text { Variáveis } \\
\text { independentes }\end{array}$ & Coef. & Prob. & Coef. & Prob. \\
\hline $\begin{array}{l}\text { Redes sociais } \\
\text { Diversidade de opiniões }\end{array}$ & $\begin{array}{c}0,093 \\
(0,079)\end{array}$ & 0,024 & $\begin{array}{c}0,144+ \\
(0,077)\end{array}$ & 0,038 \\
Conflito de opiniões & $\begin{array}{c}-0,114 \\
(0,072)\end{array}$ & $-0,029$ & $\begin{array}{c}-0,251 * * * \\
(0,064)\end{array}$ & $-0,066$ \\
\hline $\begin{array}{l}\text { Contexto social } \\
\text { Bairro - Diversidade de } \\
\text { opiniões }\end{array}$ & $\begin{array}{c}0,147 \\
(0,114)\end{array}$ & 0,038 & & \\
$\begin{array}{l}\text { Bairro - Conflito de } \\
\text { opiniões }\end{array}$ & $\begin{array}{c}-1,030 * * * \\
(0,209)\end{array}$ & $-0,269$ & & \\
\hline $\begin{array}{l}\text { Controle } \\
\text { Informação política }\end{array}$ & $\begin{array}{c}0,078 \\
(0,188)\end{array}$ & 0,020 & $\begin{array}{c}0,060 \\
(0,186)\end{array}$ & 0,015 \\
\hline $\begin{array}{l}\text { Atenção à campanha } \\
\text { política }\end{array}$ & $\begin{array}{c}0,022 \\
(0,040)\end{array}$ & 0,005 & $\begin{array}{c}0,029 \\
(0,040)\end{array}$ & 0,007 \\
\hline Atenção à televisão & $\begin{array}{c}0,165 \\
(0,147)\end{array}$ & 0,043 & $\begin{array}{c}0,177 \\
(0,145)\end{array}$ & 0,047 \\
\hline
\end{tabular}




\begin{tabular}{|l|c|c|c|c|}
\hline & \multicolumn{2}{|c|}{$\begin{array}{c}\text { Modelo 1 } \\
\text { (preferido) }\end{array}$} & \multicolumn{2}{c|}{ Modelo 2 } \\
\hline $\begin{array}{l}\text { Variáveis } \\
\text { independentes }\end{array}$ & Coef. & Prob. & Coef. & Prob. \\
\hline Atenção ao jornal & $\begin{array}{c}0,037 \\
(0,138)\end{array}$ & 0,009 & $\begin{array}{c}0,022 \\
(0,109)\end{array}$ & 0,005 \\
\hline Mulher & $\begin{array}{c}0,097 \\
(0,093)\end{array}$ & 0,025 & $\begin{array}{c}0,072 \\
(0,091)\end{array}$ & 0,019 \\
\hline Branco & $\begin{array}{c}0,177+ \\
(0,096)\end{array}$ & 0,047 & $\begin{array}{c}0,153+ \\
(0,077)\end{array}$ & 0,041 \\
\hline Educação & $\begin{array}{c}0,026 \\
(0,057)\end{array}$ & 0,006 & $\begin{array}{c}0,037 \\
(0,057)\end{array}$ & 0,009 \\
\hline Renda & $\begin{array}{c}-0,000 \\
(0,000)\end{array}$ & $-0,000$ & $\begin{array}{c}-0,000 \\
(0,000)\end{array}$ & $-0,000$ \\
\hline Idade & $\begin{array}{c}-0,000 \\
(0,003)\end{array}$ & $-0,000$ & $\begin{array}{c}-0,001 \\
(0,002)\end{array}$ & $-0,000$ \\
\hline Evangélico & $\begin{array}{c}-0,076 \\
(0,133)\end{array}$ & $-0,020$ & $\begin{array}{c}-0,241+ \\
(0,127)\end{array}$ & $-0,069$ \\
\hline Constant & $\begin{array}{c}0,756 * \\
(0,343)\end{array}$ & & $\begin{array}{c}0,575 * \\
(0,230)\end{array}$ & \\
\hline Pseudo R $\mathrm{R}^{2}$ & 0,050 & & 0,027 & \\
\hline McFadden's $\mathrm{R}^{2}$ & 0,049 & & 0,027 & \\
\hline $\mathrm{N}$ & 1.147 & & 1.151 & \\
\hline
\end{tabular}

Fonte: Pesquisa eleitoral em duas cidades brasileiras, Universidade de Pittsburgh/National Science Foundation, 2002.

Significância: $+p<0,10, * p<0,05, * * p<0,01, * * * p<0,001$.

Nota: Os valores da tabela são resultados de uma regressão probit robusta. Entre parênteses estão os errospadrão. Na última coluna estão os resultados probabilísticos do efeito marginal das variáveis independentes sobre o voto correto.

\section{Discussão}

As evidências indicam que as interações individuais determinam o voto correto no Brasil, corroborando a hipótese central do artigo de que existe uma lógica social do voto correto em uma jovem democracia em substituição aos mecanismos institucionais. Os entraves institucionais, como fragmentação partidária, baixa identidade partidária, extensa lista de candidatos e desigualdade informacional, não são obstáculos intransponíveis para o voto correto. Os brasileiros encontraram um caminho para votar corretamente através das conversas interpessoais.

Ademais, este artigo resgata a importância do contexto social para o comportamento político. Como visto, o ato de votar corretamente sofre influência do contexto em que as pessoas se encontram, por isso a importância de testar essa variável. Cabe também ressaltar que sem as variáveis de contexto social, alguns efeitos dos atributos de rede social surgiram ou, quando já existia certo efeito, o coeficiente aumentou. Nesse sentido, desagregar as variáveis de rede e contexto social, usando os atributos de diversidade e conflito, demonstrou ser uma estratégia apropriada, já que resultados empíricos significativos foram encontrados. 
Mais especificamente, essa decomposição da rede e do contexto social demonstra que as relações interpessoais são formadas por distintas dimensões. O efeito encontrado do atributo de diversidade para o voto correto abre uma nova perspectiva de pesquisa, já que a maioria dos trabalhos adota somente a variável "conflito" em suas análises. Consequentemente, alguns resultados discrepantes dessa literatura podem ser explicados com a inclusão da variável "diversidade". Pesquisadores devem também investigar a existência de outros atributos das relações sociais. Os distintos padrões de comunicação afetam de forma diferente o comportamento político.

O atributo de conflito, especificamente, tem benefícios e desvantagens para a democracia. Se ouvir opiniões de conflito à nossa opinião gera mais tolerância e um maior entendimento sobre os vários ângulos de uma questão, o conflito de opiniões também produz um desestímulo à participação política e reduz as chances do voto correto. Esse paradoxo precisa ser enfrentado pela literatura de forma definitiva. De um lado, o problema é não testar outros atributos das relações sociais, de outro lado, o problema é que a medida de conflito é codificada de forma diferente pelos especialistas, o que gera confusão e resultados mistos.

Em uma agenda futura, cabe testar o impacto das conversas interpessoais sobre uma nova medida do voto correto. Primeiro, o item de questões políticas (issues) do voto correto é baseado no modelo direcional, no entanto, pode-se codificar pelo modelo de proximidade do voto (Downs, 1957). Trata-se de uma medida mais apropriada ao sistema político brasileiro. Em segundo lugar, o voto correto baseia-se na percepção do indivíduo quanto à posição política e ideológica dos candidatos. O eleitor pode assumir tal posição como sua por já ter escolhido anteriormente o candidato no qual votar, de modo que o índice de voto correto para os Estados Unidos e o Brasil pode estar inflado. Desse modo, uma medida alternativa é usar as avaliações de especialistas para posicionar politicamente e ideologicamente os candidatos. Essas novas medidas para operacionalizar o voto correto podem enriquecer a literatura. Ainda como agenda futura, fruto do debate sobre o voto correto no Brasil, cabe investigar o nível de convergência entre a opinião pública e as políticas públicas implementadas pelos governantes como parâmetro de avaliação da representação política e da responsividade eleitoral.

Resta saber, também, se os índices encontrados de voto correto para o primeiro (67\%) e segundo turnos ( $80 \%$ ) são suficientes para o bom funcionamento da democracia brasileira. Se os eleitores que votaram incorretamente tivessem mais informações e assim tivessem votado corretamente, o resultado da eleição mudaria (Bartels, 1996; Althaus, 1998)? Essa é uma pergunta ainda sem resposta.

Por fim, este artigo contribui para o avanço da literatura, ainda incipiente sobre rede social na América Latina, e particularmente no Brasil, além de revelar que as interações individuais afetam a qualidade da democracia.

André Bello - Doutorando em Ciência Política, Instituto de Ciência Política, Universidade de Brasília. E-mail: <andrebellosa@gmail.com>. 


\section{Referências bibliográficas}

Althaus, S. L. "Information effects in collective preferences". American Political Science Review, vol. $92, n^{\circ} 3$, p. 545-558, 1998.

AMES, B. "Electoral strategy under open-list proportional representation". American Journal of Political Science, p. 406-433, 1995.

. Os entraves da democracia no Brasil. Rio de Janeiro: Editora FGV, 2003.

Baker, A.; Ames, B.; Rennó, L. R. "Pesquisa eleitoral em duas cidades brasileiras". Universidade de Pittsburgh/National Science Foundation, 2002.

"Social context and campaign volatility in new democracies: networks and neighborhoods in Brazil's 2002 elections". American Journal of Political Science, vol. 50, n², p. 382-399, 2006.

BARTELS, L. M. "Uninformed votes: information effects in presidential elections". American Journal of Political Science, vol 40, nº 1, p. 194-230, 1996.

BAYBECK, B.; MCCLURG, S. D. "What do they know and how do they know it? An examination of citizen awareness of context". American Politics Research, vol. 33, n 4, p. 492-520, 2005.

Berelson, B. "Democratic theory and public opinion". Public Opinion Quarterly, vol. 16, n 3, p. 313$330,1952$.

BURT, R. Structural holes: the social structure of competition. Boston: Harvard University Press, 1992.

CAMPBeLL, A. The american voter. Chicago: University of Chicago Press, 1980.

CAMPBelL, A., et al. The American voter. Survey Research Center, Michigan: University of Michigan, 1960.

CARPINI, M. X. D.; KeETER, S. What Americans know about politics and why it matters. New Haven: Yale University Press, 1997.

CONVERSE, P. E. The nature of belief systems in mass publics. Survey Research Center, University of Michigan, 1964.

DAHL, R. A. "The concept of power". Behavioral Science, vol. 2, n 3, p. 201-215, 1957.

. Um prefácio à teoria democrática. Rio de Janeiro: Jorge Zahar Editora, 1989.

$\overline{1997 .}$ . Poliarquia: participação e oposição. Trad.: C. Paciornik. Pref.: F. Limongi. São Paulo: Edusp,

DiAmond, L. J.; MORLINo, L. (eds.). Assessing the quality of democracy. Baltimore: Johns Hopkins University Press, 2005.

Downs, A. An economic theory of democracy. New York: Harper and How, 1957.

FIELD, A. Discovering statistics using SPSS. London: Sage publications, 2009.

GiLENS, M. "Political ignorance and collective policy preferences". American Political Science Association, vol. 95, $\mathrm{n}^{\circ}$ 2, p. 379-396, 2001. 
Granovetter, M. S. "The strength of weak ties". American Journal of Sociology, vol. 78, p. 1.360$1.380,1973$.

HUCKFELDT, R. "Political participation and the neighborhood social context". American Journal of Political Science, vol. 23, p. 579-592, 1979.

. "Social contexts, social networks, and urban neighborhoods: environmental constraints on friendship choice". American Journal of Sociology, vol. 89, p. 651-669, 1983.

Citizens, politics and social communication: information and influence in an election campaign. New York: Cambridge University Press, 1995.

Information, and political communication networks. In: DALTON, R.; KLINGEMANN, H. (eds.). The Oxford Handbook of Political Behavior. New York: Oxford University Press, 2007.

HUCKFELDT, R.; SPRAgUe, J. "Networks in context: the social flow of political information". American Political Science Review, vol. 81, nº 4, p. 1.197-1.216, 1987.

. Citizens, politics and social communication: information and influence in an election campaign. New York: Cambridge University Press. 1995.

Huckfeldt, R.; Johnson, P. E.; Sprague, J. "Political environments, political dynamics, and the survival of disagreement", The Journal of Politics, vol. 64, n 1, p. 1-21, 2002.

. Political disagreement: the survival of diverse opinions within communication networks. New York: Cambridge University Press, 2004.

Huntington, S. P. A terceira onda: a democratização no final do século XX. São Paulo: Ática, 1994.

KaTz, E. "The two-step flow of communication: An up-to-date report on an hypothesis". Public Opinion Quarterly, vol. 21, n 1, p. 61-78, 1957.

Katz, E.; Lazarsfeld, P. F. Personal influence: the part played by people in the flow of mass communications. New Jersey: Transaction Pub, 1955.

KLOFSTAD, C. A. "Talk leads to recruitment how discussions about politics and current events increase civic participation". Political Research Quarterly, vol. 6, n² 2, p. 180-191, 2007.

. "Civic talk and civic participation. The moderating effect of individual predispositions". American Politics Research, vol. 37, nº 5, p. 856-878, 2009.

KLOFSTAD, C. A.; SOKHEY, A. E.; MCCluRG, S. D. "Disagreeing about disagreement: how conflict in social networks affects political behavior". American Journal of Political Science, vol. 57, no 1, p. 120-134, 2013.

LAU, R. R.; ANDERSEN, D. J.; RedLAWSK, D. P. "An exploration of correct voting in recent US presidential elections". American Journal of Political Science, vol. 52, $\mathrm{n}^{\circ} 2$, p. 395-411, 2008.

LAU, R. R.; Redlawsk, D. P. "Voting correctly". American Political Science Review, vol. 91, n 3, p. 585-598, 1997.

- How voters decide: information processing during election campaigns. Cambridge: Cambridge University Press, 2006.

. "Advantages and disadvantages of cognitive heuristics in political decision making. American Journal of Political Science, vol. 45, n 4, p. 951-971, 2001. 
LAU, R. R., et al. "Correct voting across thirty-three democracies: a preliminary analysis". British Journal of Political Science, vol. 44, n² 2, p. 239-259, 2014.

LazARsfeld, P. F.; Berelson, B.; Gaudet, H. The people's choice: how the voter makes up his mind in a presidential campaign. New York: Columbia, 1948.

LIMA, R. C. "Modelos de respostas binárias: especificação, estimação e inferência". Agricultura em São Paulo, vol. 43, p. 19-26, 1996.

LUPIA, A. "Shortcuts versus encyclopedias: information and voting behavior in California insurance reform elections". American Political Science Review, vol. 88, n¹, p. 63-76, 1994.

LUPIA, A.; McCubBins, M. D. The democratic dilemma: can citizens learn what they need to know? Cambridge: Cambridge University Press, 1998.

MacKuen, M.; Brown, C. "Political context and attitude change". American Political Science Review, vol. $81, \mathrm{n}^{\circ} 2$, p. $471-490,1987$.

MAINWARING, S. "Politicians, parties, and electoral systems: Brazil in comparative perspective". Comparative Politics, vol. 24, n 1, p. 21-43, 1991.

MCCLURG, S. D.; YounG; J. K. "A relational political science". Working Paper, vol. 45, 2010.

MCClURG, S. D.; SOKHEY, A. E. "Social networks and correct voting". Working Papers, p. 3, 2009.

Mondak, J. J. "Public opinion and heuristic processing of source cues." Political Behavior, vol. 15, $n^{\circ}$ 2, p. 167-192, 1993.

MUTZ, D. C. Impersonal influence: how perceptions of mass collectives affect political attitudes. Cambridge: Cambridge University Press, 1998.

"The consequences of cross-cutting networks for political participation". American Journal of Political Science, vol. 46, n 4, p. 838-855, $2002 \mathrm{a}$.

. "Cross-cutting social networks: testing democratic theory in practice". American Political Science Review, vol. 96, n 1, p. 111-126, 2002b.

. Hearing the other side: deliberative versus participatory democracy. New York: Cambridge University Press, 2006.

MUTZ, D. C.; MARTIN, P. S. "Facilitating communication across lines of political difference: the role of mass media". American Political Science Review, vol. 95, nº 1, p. 97-114, 2001.

MUTZ, D. C.; MondaK, J. J. "The workplace as a context for cross-cutting political discourse". Journal of Politics, vol. 68, n 1, p. 140-155, 2006.

NIR, L. "Ambivalent social networks and their consequences for participation". International Journal of Public Opinion Research, vol. 17, n 4, p. 422-442, 2005.

. "Disagreement and opposition in social networks: does disagreement discourage turnout?". Political Studies, vol. 59, n³, p. 674-692, 2011.

PATEL, P. "The effects of institutions on correct voting". PhD thesis, Rutgers University-Graduate School-New Brunswick, 2011.

POPKIN, S. L. The reasoning voter: communication and persuasion in presidential campaigns. Chicago: University of Chicago Press, 1991. 
Putnam, R. D. "Political attitudes and the local community". American Political Science Review, vol. $60, n^{\circ} 3$, p. 640-654, 1966.

Bowling alone: the collapse and revival of American community. New York: Simon and Schuster, 2000.

RENNÓ, L. "Desigualdade e informação política: as eleições brasileiras de 2002". Dados, vol. 50, n 4, p. 721-755, 2007.

. "Qualidade da representação de interesses no Brasil". Cepal. Escritório no Brasil/Ipea. Brasília-DF, 2010.

RenNó, L., et al. Legitimidade e qualidade da democracia no Brasil: uma visão da cidadania. São Paulo: Intermeios, 2011.

Richey, S. "The social basis of voting correctly". Political Communication, vol. 25, n 4, p. 366-376, 2008.

RYAN, J. B. "Social networks as a shortcut to information and correct voting". In: APSA Toronto Meeting Paper, 2009.

WALGRAVE, S., et al. "Why representation fails. Determinants of incorrect voting in a crowded party system". In: NCCR Democracy Workshop on Political Representation "New Ways of Measuring and Old Challenges", vol. 12, 2009.

\section{Resumo}

\section{A lógica social do voto correto no Brasil}

Este artigo trata do papel das interações sociais sobre o voto correto na perspectiva de avaliar a qualidade da democracia no Brasil. Nas novas democracias, o sistema político complexo multipartidarismo, voto personalista, identificação partidária fraca e múltiplos candidatos - pode prejudicar o voto correto. Argumento, principalmente, que as redes interpessoais e o contexto social funcionam como atalhos cognitivos, substituindo os mecanismos institucionais. As redes interpessoais e o contexto social são desagregados pelos atributos de conflito e diversidade, os quais influenciam distintamente $\mathrm{o}$ ato de votar corretamente. $\mathrm{O}$ resultado confirma a ideia de que existe uma lógica social do voto correto.

Palavras-chave: redes sociais; contexto social; voto correto; comportamento político

\section{Abstract}

The social logic of correct voting in Brazil

This article analyzes the role that social interactions play in shaping correct voting in order to assess the quality of democracy in Brazil. In new democracies, complex political systems-multi-party, personalistic voting, weak partisan identification, and too many candidates in the race-may undermine correct voting. The main argument is that interpersonal networks and social context function as cognitive shortcuts replacing institutional mechanisms. Interpersonal networks and social context are disaggregated into the attributes of conflict and diversity, which distinctively influence correct voting. The results confirm that a social logic of correct voting indeed exists.

Keywords: social network; social context; correct voting; political behavior 


\section{Resumen}

La lógica social del voto correcto en Brasil

Este artigo trata el rol de las interacciones sociales sobre el voto correcto en la perspectiva de evaluar la calidad de la democracia en Brasil. En las nuevas democracias el sistema político complejo (multipartidario, el voto personalista, la identificación partidaria débil y de múltiples candidatos) puede perjudicar el voto correcto. Argumento, principalmente, que las redes interpersonales y el contexto social funcionan como atajos cognitivos, sustituyendo los mecanismos institucionales. Las redes interpersonales y el contexto social se separan por los atributos de conflicto y diversidad, los cuales influencian distintamente el acto de votar correctamente. El resultado confirma la idea de que existe una lógica social del voto correcto.

Palabras-Ilave: redes sociales; voto correcto; comportamiento político; nueva democracia.

\section{Résumé}

La logique sociale du vote correct au Brésil

Cet essai traite du rôle des interactions sociales sur le vote correct, en vue d'une évaluation qualitative de la démocratie au Brésil. Il est vrai que dans les nouvelles démocraties le système politique complexe - prolifération des partis, vote personnaliste, faible identification envers un parti, grands nombre de candidats - peut porter préjudice au vote correct. Notre principal argument est que les réseaux interpersonnels ainsi que le contexte social fonctionnent comme des raccourcis cognitifs qui remplacent les mécanismes institutionnels; ils sont donc désagrégés par les attributs du conflit et de la diversité qui influencent clairement l'action de voter correctement. Le résultat vient corroborer l'idée selon laquelle il existe une logique sociale du vote correct.

Mots-clés: réseaux sociaux; contexte social; suffrage correct; comportement politique

Artigo submetido à publicação em maio de 2015. Versão final aprovada em abril de 2016. 